\title{
Chronic Acamprosate Eliminates the Alcohol Deprivation Effect While Having Limited Effects on Baseline Responding for Ethanol in Rats
}

Charles J. Heyser, Ph.D., Gery Schulteis, Ph.D., Philippe Durbin, Ph.D., and George F. Koob, Ph.D.

Acamprosate (calcium-acetyl homotaurinate) is a relatively new compound developed for the treatment of alcoholism and has been shown to be effective in attenuating relapse in human alcoholics. In the current study, the effects of this drug were further examined using an animal model of oral ethanol self-administration in a limited access paradigm. Male Wistar rats were trained to respond for ethanol $(10 \%$ $w / v)$ or water in a two-lever free-choice operant condition. Acute administration of acamprosate $(400 \mathrm{mg} / \mathrm{kg})$ reduced ethanol consumption and increased responding for water. Chronic administration of lower daily doses of acamprosate
(100 and $200 \mathrm{mg} / \mathrm{kg}$ ) blocked the increased ethanol consumption typically observed in rats after an imposed abstinence period. This effect of acamprosate was selective for ethanol, as responding for water was unaffected at any dose tested. These results with rats suggest a model by which to explore the mechanisms for anti-relapse effects of acamprosate. [Neuropsychopharmacology 18:125-133, 1998] (C) 1998 American College of Neuropsychopharmacology. Published by Elsevier Science Inc.
KEY WORDS: Ethanol; Self-Administration; Abstinence; Alcohol deprivation effect; Acamprosate; Relapse

The potential therapeutic action of several compounds has been examined for the treatment of alcoholism including disulfiram, lithium, serotonin uptake inhibitors, naloxone, and acamprosate (Naranjo et al. 1986, 1987; Litten et al. 1996; Schuckit 1996). One of these, acamprosate (calcium acetylhomotaurinate), has generated wide research attention in Europe for the treatment of alcoholism (Litten et al. 1996). Acamprosate is a synthetic derivative of homotaurinate, which is a natu-

From the Scripps Research Institute (CJH, GS, GFK), Department of Neuropharmacology, La Jolla, California, and the Centre de Recherche, Groupe Lipha (PD), Lyon, France.

Address correspondence to: Charles J. Heyser, Ph.D., Department of Neuropharmacology, The Scripps Research Institute, 10550 North Torrey Pines Road, CVN-7, La Jolla, CA 92037.

Received April 22, 1997; revised June 26, 1997; accepted August 27, 1997. rally occurring structural analog of $\gamma$-aminobutyric acid (GABA) (Chick 1995). The precise mechanism for acamprosate has yet to be determined as there may be multiple sites of action for this drug. It has been shown to cross the blood-brain barrier and to have neuropharmacological actions (Boismare et al. 1984; Chabenat et al. 1988; Daoust et al. 1992). Acamprosate reduces the postsynaptic efficacy of excitatory amino acid neurotransmitters and lowers neuronal excitability in the neocortex of the rat (Zeise et al. 1993). More recent data show that acamprosate may act postsynaptically to increase the n-methyl-d-aspartate (NMDA) component of excitatory transmission to principal neurons in both hippocampal CA1 and nucleus accumbens (Madamba et al. 1996; Berton et al. in press). More specifically, acamprosate may act through the glycine site of the NMDA receptor in the hippocampus (Madamba et al. 1996) and by inhibiting the function of presynaptic $\mathrm{GABA}_{\mathrm{B}}$ receptors in the nucleus accumbens (Berton et 
al. in press). Additional results suggest that acamprosate may act directly on the polyamine site of the NMDA receptor (Durbin et al. 1996), thereby modulating the activity of these receptors that appear to be critically involved in the effects of alcohol (Madamba et al. 1996; Spanagel et al. 1996c).

Initial studies in humans reported that alcoholics treated with acamprosate were more likely to remain abstinent than those given placebo (Lhuintre et al. 1985). Similar results were reported in a later study, which reported lower gamma-glutamyl transpeptidase (GGT) levels in acamprosate-treated alcoholics than in placebo-treated controls (Lhuintre et al. 1990). More recently, a large 31-site double-blind, placebo-controlled study was conducted in which alcohol dependent patients received acamprosate or placebo in addition to psychotherapy for 1 year (Paille et al. 1995). The results of this study show that alcoholics treated with acamprosate had significantly longer periods of abstinence when compared with placebo-treated subjects at 6 months and 12 months. Other multicenter, double-blind, placebo-controlled studies reported similar results with significantly more acamprosate-treated subjects maintaining abstinence than placebo-treated subjects (Sass et al. 1996; Whitworth et al. 1996).

Animal studies provide further evidence that acamprosate affects alcohol-related behaviors. For example, acamprosate has been shown to reduce alcohol intake in rats without influencing total fluid and food intake (Boismare et al. 1984; Le Magnen et al. 1987b; Daoust et al. 1992; Rassnick et al. 1992). This reduction in ethanol intake may be due to changes in the reinforcing efficacy of alcohol. Initial reports showed that acamprosate did not alter ethanol toxicity as tested by ethanol-induced hypothermia, motor impairment and taste aversion in ethanol-naive rats (Le Magnen et al. 1987a). However, Spanagel et al. (1996b) have reported that acamprosate does reduce some of the signs of ethanol withdrawal. Therefore, the mechanism (both neurochemical and behavioral) through which acamprosate is working to reduce ethanol intake in rats and to attenuate relapse in humans is relatively unknown.

The majority of animal work with acamprosate has been conducted in dependent animals or those with a high intake of ethanol. More appropriate for the study of a potential anti-relapse medication is an animal model of transient excessive ethanol self-administration after a period of abstinence. Therefore, the present study was conducted to characterize the effects of acamprosate on baseline responding for ethanol and during a period of abstinence using an operant model of alcohol seeking behavior in a limited access paradigm. An increase in ethanol consumption is typically observed after a period of abstinence in rats (Le Magnen 1960; Sinclair and Senter 1967, 1968; Wolffgramm and Heyne 1995; Spanagel et al. 1996a; Heyser et al.
1997), monkeys (Kornet et al. 1990), and in human social drinkers (Burish et al. 1981). This effect has been termed the "alcohol deprivation effect" (Sinclair and Senter 1967) and may be relevant to the study of abstinence conditions seen in human alcoholics. It is well established that in alcoholics, even after withdrawal and after having been alcohol free for some time, relapses into problematic alcohol drinking frequently occur (Hunt et al. 1971; Mendelson and Mello 1979; Marlatt and George 1984; Yates et al. 1994) and form a wellknown and serious problem in the treatment of alcoholism (Barnes 1988).

\section{MATERIALS AND METHODS}

\section{Subjects}

Subjects were 120 male Wistar rats (Charles River Laboratory, Hollister, CA). Rats were housed in groups of two to three per cage in a temperature- and humiditycontrolled environment with a 12-h light/dark cycle (lights on at 10:00 P.M.). Food and water were available ad libitum, except as noted in the procedure. All procedures were conducted in accordance with the guidelines established by the National Institutes of Health in the Guide for the Care and Use of Laboratory Animals.

\section{Apparatus}

Ethanol self-administration training was conducted in standard operant chambers (Coulbourn Instruments, Allentown, PA) that were located in sound-attenuated, ventilated environmental cubicles. Two $35-\mathrm{ml}$ syringes dispensed either ethanol or water through plastic tubing into two stainless-steel drinking cups mounted $4 \mathrm{~cm}$ above the grid floor and centered on the front panel of each chamber. Each drinking cup could hold approximately two reinforcer deliveries $(0.2 \mathrm{ml})$. Two retractable levers were located $4.5 \mathrm{~cm}$ to either side of the drinking cups. Fluid delivery and recording of operant responses were controlled by microcomputer.

\section{Procedure}

Operant Procedure for Oral Ethanol Self-Administration Training. All rats were trained to respond for ethanol or water in a two-lever free-choice situation. The procedure for induction of oral ethanol self-administration is a modification of Samson and colleagues and has been successfully used previously in our laboratory (Samson 1986; Schulteis et al. 1996). Rats were subjected to a 22-hour water deprivation schedule only during the first 3 days of training (no ethanol was available during this period of training). Self-administration training was initiated in operant chambers by allowing 
rats to press either of two levers for a $0.2 \%(\mathrm{w} / \mathrm{v})$ saccharin solution on a continuous reinforcement schedule ( $0.1 \mathrm{ml}$ fluid/response) in 30-min daily sessions. After this initial training phase and throughout the remainder of training and testing, water was freely available in the home cage. Starting on day 4 , rats were trained to alternate responding on the right and left lever (i.e., left, right, left, right, etc.) to obtain a $5.0 \%$ ethanol $+0.2 \%$ saccharin $(\mathrm{w} / \mathrm{v})$ solution. The alternation procedure was used to reduce positional (lever) biases in responding. Starting on day 9 , both levers were made available in a free-choice situation, with one lever producing an ethanol solution and the other lever producing water. During the next 10 days of training, ethanol concentrations were gradually increased to 8.0 and then $10.0 \%$ ethanol $(w / v)$. At the same time, saccharin concentrations were decreased to $0 \%$. The lever that produced ethanol continued to alternate from left to right on consecutive days to prevent establishment of a positional bias in responding. This procedure also maintains stable responding for both alcohol and water and permits a more stringent test of ethanol preference for animals, as the animals must track and respond to the appropriate lever necessary for obtaining ethanol. Rats were allowed to stabilize their intake of $10 \%$ ethanol (without saccharin) and water for 15 to 25 days and meet an established criterion for ethanol intake before being randomly assigned to the experimental groups. The criterion for stable responding was defined as $\pm 20 \%$ of the previous day's total number of responses for ethanol for three consecutive sessions. All testing and training was conducted during the animal's dark cycle.

Ethanol Deprivation Procedure. After establishment of stable responding for ethanol, a 5-day deprivation period was imposed during which time ethanol was not available. During this period of ethanol deprivation, rats remained in their home cages with food and water available ad libitum.

\section{Experiment 1: Effects of Acute Injection of Acamprosate on Baseline Responding for Ethanol and after a Period of Ethanol Deprivation}

Acamprosate was dissolved in saline, and all drugs were administered by intraperitoneal (IP) injection 30 min before the start of the session. To test nonspecific effects of the injection process and also to familiarize the rats to this procedure, all rats were initially tested after saline administration. Twenty-four hours later, one group of animals ( $n=8$ per group; total $n=24$ ) was tested after a single administration of acamprosate $(100,200$, or $400 \mathrm{mg} / \mathrm{kg})$. A separate group of animals ( $n=8$ per group; total $n=24$ ) was tested after receiving a single injection of saline or acamprosate (200 or 400 $\mathrm{mg} / \mathrm{kg}$ ) after 5 days of ethanol deprivation.

\section{Experiment 2: Effects of Chronic Injections of Acamprosate on Baseline Responding for Ethanol and after a Period of Ethanol Deprivation}

This experiment was similar to experiment 1 , except that animals received chronic (twice daily) injections of acamprosate for 5 days. Injections (IP) of saline or acamprosate $(25,100$, or $200 \mathrm{mg} / \mathrm{kg})$ were made at $12-\mathrm{h}$ intervals at approximately 6:00 A.M. and 6:00 P.M. To examine the effect on baseline responding, each daily session was conducted $30 \mathrm{~min}$ after the second injection. A separate group of rats ( $n=10$ per group; total $n=40$ ) received saline or acamprosate $(25,100$, or $200 \mathrm{mg} / \mathrm{kg})$ throughout a 5-day period of ethanol deprivation. Animals in this group were tested $30 \mathrm{~min}$ after the last injection on day 5 .

\section{Data Analysis}

Results of the operant procedure are reported as the mean cumulative number of bar presses for ethanol and water. Data for the number of bar presses for ethanol and water were analyzed by a mixed analysis of variance (ANOVA), with days of testing and intervals as within-subjects factors. Tukey's honestly significant difference tests and simple main effects analysis (Kirk 1982) were used to determine the locus of significant and main effects and interactions. A significance level of $p<.05$ was used for all statistical analyses.

\section{RESULTS}

\section{Experiment 1}

Data analysis indicated that an acute injection of acamprosate produced a significant decrease in ethanol responding at the highest dose tested $\mathrm{F}(4,42)=13.74, p<$ .01 . As can be seen in Figure 1, ethanol responding was reduced after a single injection of acamprosate (400 $\mathrm{mg} / \mathrm{kg}$ ). This decrease in ethanol consumption was also accompanied by a significant increase in responding for water $F(4,42)=6.25, p<.01$. However, responding for both ethanol and water was significantly reduced on the day after this dose of acamprosate.

As can be seen in Figure 2, saline-treated animals deprived of ethanol for 5 days significantly increased their responding for ethanol when compared with baseline levels of responding. There was no effect of ethanol deprivation on water intake in saline-treated animals. An acute injection of acamprosate given on the last day of ethanol deprivation was effective in reducing ethanol intake only at the highest dose tested $(400 \mathrm{mg} / \mathrm{kg}$ ) (see Figure 2). This dose of acamprosate eliminated the increase in ethanol consumption typically observed after a period of ethanol deprivation and significantly reduced responding for ethanol below baseline levels 
$\mathrm{F}(4,42)=10.25, p<.01$. A corresponding increase in responding for water was observed after this dose of acamprosate (see Figure 2). However, similar to the results obtained after an acute administration of acamprosate on baseline responding for ethanol, this high dose of acamprosate $(400 \mathrm{mg} / \mathrm{kg}$ ) significantly reduced operant responding for both ethanol and water on the day after this dose.

\section{Experiment 2}

The highest doses of acamprosate $(400 \mathrm{mg} / \mathrm{kg})$ used in experiment 1 (the acute effects) were not tested in the chronic situation given its long-term suppressing effects on operant responding. However, as can be seen in Table 1, chronic administration of acamprosate at doses of 25,100 , and $200 \mathrm{mg} / \mathrm{kg}$ produced no significant ef-
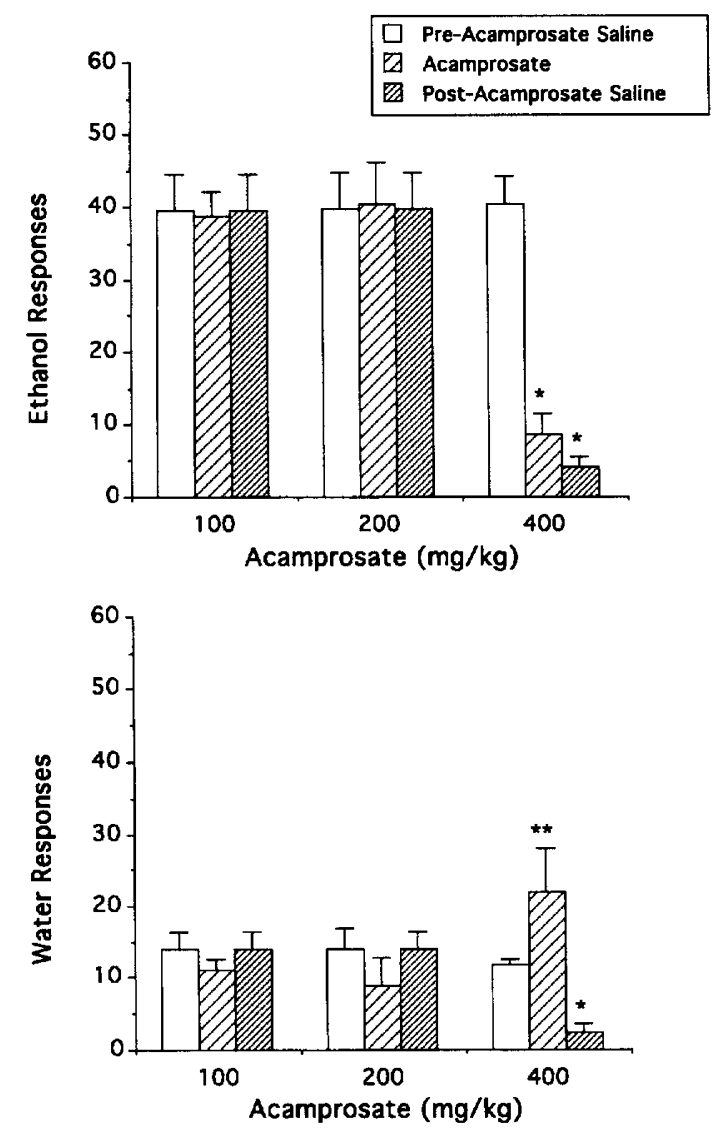

Figure 1. The mean total responses for ethanol (top) and water (bottom) after acute administration of saline or acamprosate during the $30-\mathrm{min}$ limited access operant session. A single injection of acamprosate $(400 \mathrm{mg} / \mathrm{kg})$ significantly reduced responding for ethanol and increased responding for water. Operant responding for both ethanol and water was significantly reduced on the day after the highest dose of acamprosate. Data are presented as mean + SE. ${ }^{* *}$ Indicates significantly greater than baseline $(p<.05)$ * Indicates significantly less than baseline $(p<.05)$. fects on baseline (nondeprived) responding for ethanol or water (all Fs $<1.0$ ).

By contrast, the results of chronic administration of acamprosate during a period of ethanol deprivation revealed a significant effect of this drug on behavior. The ANOVA conducted on the cumulative number of barpresses for ethanol revealed a significant main effect of time $\mathrm{F}(5,180)=154.75, p<.01$, along with significant interactions of dose $\times$ day $\mathrm{F}(6,72)=2.72, p<.01$, day $\times$ time $F(10,360)=3.79, p<.01$ and a significant overall
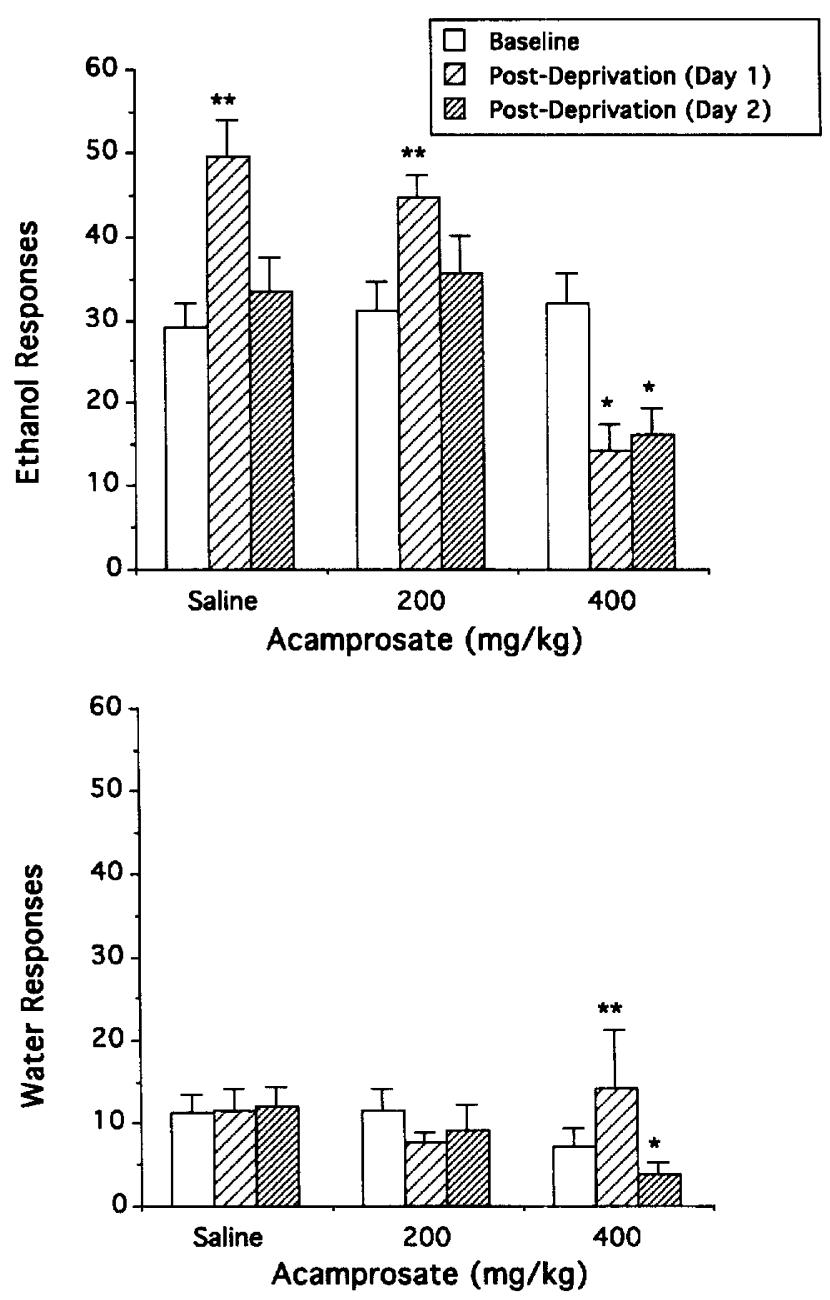

Figure 2. The effect of an acute administration of saline or acamprosate on responding for ethanol (top) and water (bottom) after 5 days of ethanol deprivation. Ethanol responding increased above baseline after 5 days of ethanol deprivation in animals treated with saline or $200 \mathrm{mg} / \mathrm{kg}$ acamprosate. A single administration of acamprosate significantly reduced responding for ethanol below baseline levels and increased responding for water at the highest dose tested $(400 \mathrm{mg} / \mathrm{kg})$. Operant responding for both ethanol and water was significantly reduced on the day after the highest dose of acamprosate. Data are presented as mean total responses $+\mathrm{SE}$. ${ }^{* *}$ Indicates significantly greater than baseline $(p<.05) .{ }^{*}$ Indicates significantly less than baseline $(p<.05)$. 
Table 1. Effects of Chronic Administration of Acamprosate on Baseline Responding for Ethanol

\begin{tabular}{lccccc}
\hline \multicolumn{1}{c}{ Treatment } & Day 1 & Day 2 & Day 3 & Day 4 & Day 5 \\
\hline $\begin{array}{l}\text { Responses for ethanol } \\
\quad \text { Saline }\end{array}$ & $34.2 \pm 3.0$ & $28.8 \pm 5.6$ & $27.2 \pm 4.3$ & $28.0 \pm 4.6$ & $30.0 \pm 4.0$ \\
$25 \mathrm{mg} / \mathrm{kg}$ & $30.2 \pm 4.6$ & $25.5 \pm 2.2$ & $28.2 \pm 3.2$ & $30.5 \pm 7.6$ & $28.0 \pm 2.0$ \\
$100 \mathrm{mg} / \mathrm{kg}$ & $32.5 \pm 6.0$ & $37.5 \pm 3.9$ & $29.0 \pm 5.0$ & $28.2 \pm 7.0$ & $28.0 \pm 5.7$ \\
$\quad 200 \mathrm{mg} / \mathrm{kg}$ & $32.2 \pm 3.8$ & $29.4 \pm 8.0$ & $26.3 \pm 5.0$ & $27.2 \pm 4.1$ & $24.0 \pm 6.0$ \\
Responses for water & & & & & \\
$\quad$ Saline & $12.1 \pm 2.3$ & $15.2 \pm 3.2$ & $13.1 \pm 2.1$ & $14.0 \pm 2.2$ & $12.2 \pm 2.4$ \\
$25 \mathrm{mg} / \mathrm{kg}$ & $13.3 \pm 2.1$ & $12.5 \pm 1.8$ & $10.3 \pm 1.8$ & $14.1 \pm 2.0$ & $11.3 \pm 1.9$ \\
$100 \mathrm{mg} / \mathrm{kg}$ & $13.9 \pm 2.1$ & $12.9 \pm 1.9$ & $15.0 \pm 2.2$ & $13.1 \pm 1.8$ & $10.1 \pm 2.0$ \\
$200 \mathrm{mg} / \mathrm{kg}$ & $11.1 \pm 1.4$ & $13.1 \pm 3.2$ & $12.3 \pm 2.5$ & $14.1 \pm 2.5$ & $10.3 \pm 2.0$ \\
\hline
\end{tabular}

Data presented as the mean $\pm \mathrm{SE}$.

three-way interaction of dose $\times$ day $\times$ time $F(30,360)=$ $1.82, p<.01$. To interpret this interaction, it is important to note in Figure 3 that all groups had similar intake patterns of ethanol prior to deprivation (range: 30.4 34.1 responses). As previously observed in our laboratory, animals generally make most of their responses for ethanol in the first 10 to 15 min of the session. A similar pattern of responding was observed in deprived animals during the first $10 \mathrm{~min}$, and this pattern did not differ from baseline responding. However, animals treated with saline or the lowest dose of acamprosate $(25 \mathrm{mg} / \mathrm{kg})$ during a 5-day period of ethanol deprivation continued to respond for ethanol throughout the 30-min session. This increased responding in the later stages of the session was eliminated in animals chronically treated during the deprivation period with 100 or $200 \mathrm{mg} / \mathrm{kg}$ of acamprosate. The effects of ethanol deprivation and acamprosate were selective for ethanol, and no significant alterations in responding for water were observed (see Figure 4).

\section{DISCUSSION}

In the present study, acamprosate produced a significant reduction in baseline ethanol intake at the highest
Saline

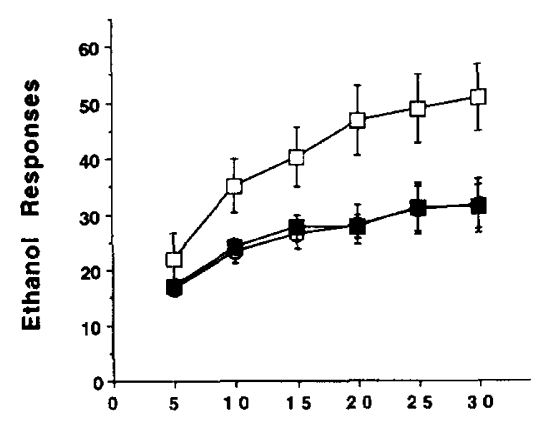

$100 \mathrm{mg} / \mathrm{kg}$ Acamprosate

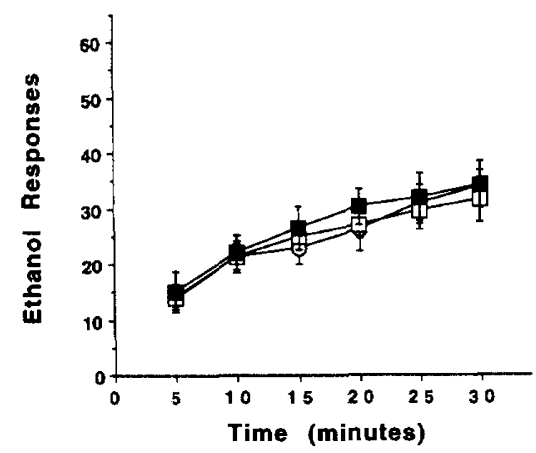

$25 \mathrm{mg} / \mathrm{kg}$ Acamprosate

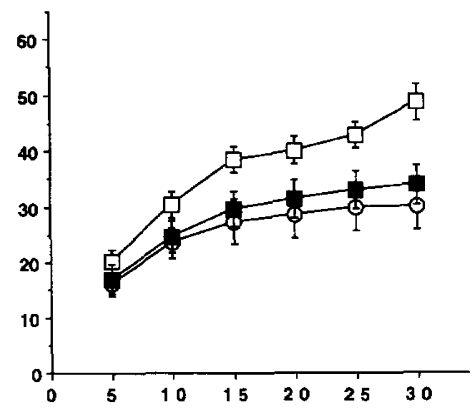

$200 \mathrm{mg} / \mathrm{kg}$ Acamprosate

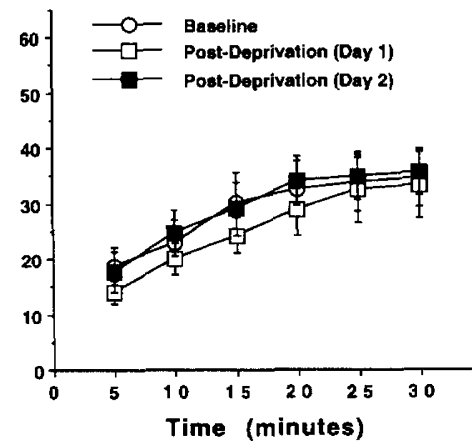

Figure 3. The effects of chronic administration of saline or acamprosate on responding for ethanol after 5 days of ethanol deprivation. Mean cumulative responses for ethanol in 5-min intervals during baseline (open circles), 1 day post-deprivation (open squares) and the second day post-deprivation (filled squares). Each panel represents a different treatment. Ethanol responding was increased above baseline after 5 days of ethanol deprivation in animals treated chronically with saline or $25 \mathrm{mg} / \mathrm{kg}$ acamprosate. Chronic administration of higher dose of acamprosate (100 or $200 \mathrm{mg} / \mathrm{kg}$ ) eliminated the deprivation-induced increase in ethanol responding. Data are presented as mean $+\mathrm{SE}$. 
dose tested $(400 \mathrm{mg} / \mathrm{kg}$ ) and significantly increased responding for water. However, operant responding for both ethanol and water was significantly reduced the day after this dose. Increased responding for ethanol was observed after a period of deprivation when compared with baseline levels of ethanol intake, confirming previous demonstrations of the alcohol deprivation effect (Le Magnen 1960; Sinclair and Senter 1967, 1968; Wolffgramm and Heyne 1995; Spanagel et al. 1996a, Heyser et al. 1997). Chronic administration of acamprosate eliminated this deprivation-induced increase in drinking. These results confirm a previous report that acamprosate affects the alcohol deprivation effect (Spanagel et al. 1996a) and extend these findings to a limited
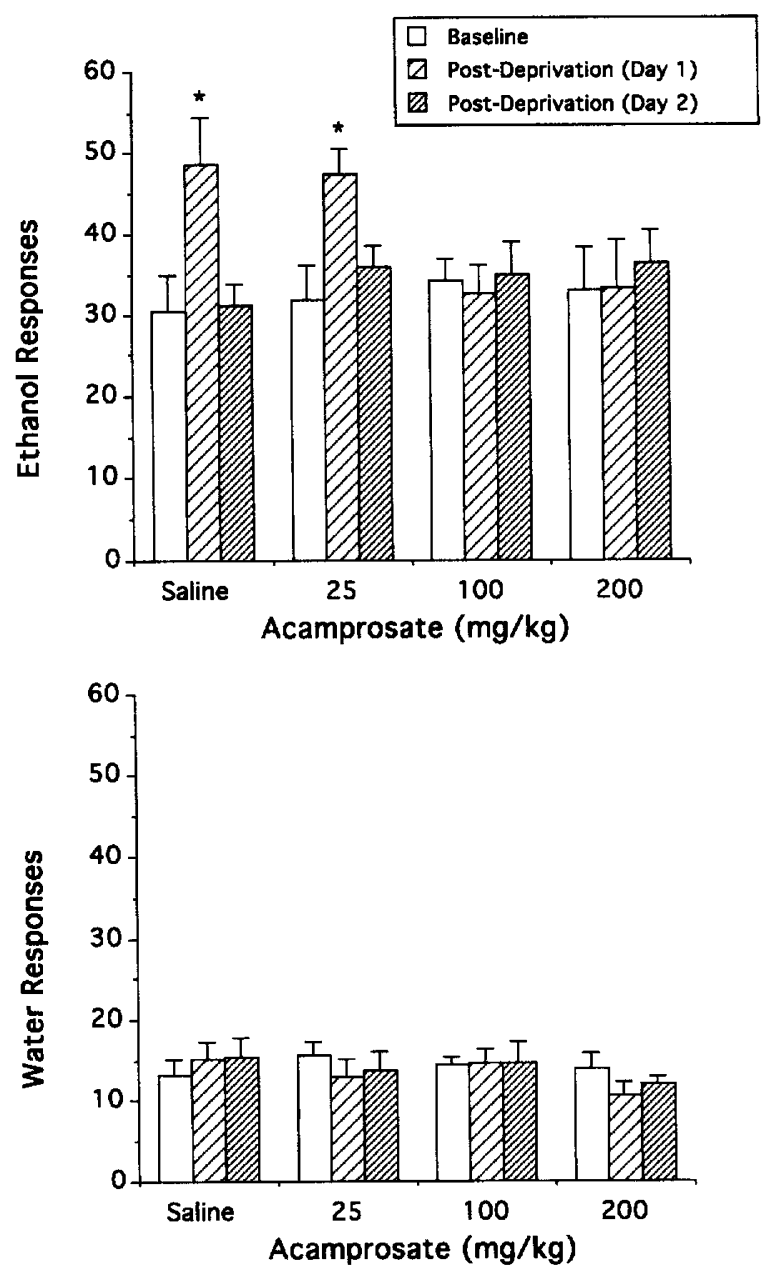

Figure 4. The effect of a chronic administration of saline or acamprosate on responding for ethanol (top) and water (bottom) after 5 days of ethanol deprivation. Ethanol responding increased above baseline after 5 days of ethanol deprivation in animals treated with saline or $25 \mathrm{mg} / \mathrm{kg}$ acamprosate. Chronic administration of acamprosate eliminated the alcohol deprivation effect without affecting water responding. Data are presented as mean total responses $+\mathrm{SE} .{ }^{*}$ Indicates significantly greater than baseline $(p<.05)$. access operant paradigm. These results support the hypothesis that acamprosate is effective in modulating aspects of alcohol-seeking behavior.

Several studies have shown that acamprosate reduces alcohol intake without influencing total fluid and food intake (Boismare et al. 1984; Le Magnen et al. $1987 \mathrm{~b}$ ). The results of the present study would appear to be inconsistent with these earlier studies. However, several methodological differences exist between these earlier studies and the present one. For example, Le Magnen et al. (1987b) reported a 50-70\% reduction in ethanol intake in ethanol dependent animals at an effective dose of acamprosate of $200 \mathrm{mg} / \mathrm{kg}$, whereas only a dose of $450 \mathrm{mg} / \mathrm{kg}$ reduced drinking in alcohol-naive animals. Boismare et al. (1984) also reported a decrease in ethanol intake in animals given chronic exposure to acamprosate $(200 \mathrm{mg} / \mathrm{kg})$. However, the rats used in this study were selected for the highest ethanol intake, and consequently only $24 \%$ of the total population of rats were tested. One purely methodological difference is that rats in the earlier studies were drinking ethanol from bottles, whereas an operant procedure was used in the present study. A more intriguing explanation for these differences is that the rats in the study by Le Magnen et al. (1987b) were ethanol dependent and the rats in the study by Boismare et al. (1984) were selected for high alcohol intake, whereas the rats in the present study were not made dependent on ethanol nor were they selected for ethanol intake. Therefore, the action of acamprosate may be strongest in populations that prefer alcohol or have a history of alcohol dependence.

Chronic administration of acamprosate resulted in an elimination of the alcohol deprivation effect and confirms a previous report by Spanagel et al. (1996a). These authors reported that acamprosate decreased the alcohol deprivation effect and at the highest dose $(200 \mathrm{mg} /$ $\mathrm{kg}$ ) tested reduced ethanol intake below baseline levels. The baseline responding for ethanol was not altered in the current study. The rats in the study by Spanagel et al. (1996a) had 24-h access to bottles of ethanol for 8 months prior to acamprosate administration. In contrast, animals in the present study were only trained to stable baseline (about 2 to 3 months) and in a limited access paradigm ( $30 \mathrm{~min} /$ day). Whereas saline-treated animals in both studies exhibited a robust deprivation effect, taste adulterations, such as the addition of quinine to the alcohol solution, eliminated the alcohol deprivation effect in animals trained for 2 months but had no effect in animals trained 8 months (Spanagel 1996a). These findings provide further support for the hypothesis that the effectiveness of acamprosate may be related to the history of alcohol experience.

It is important to note that although acamprosate has been shown in previous studies to reduce ethanol intake without influencing total fluid and food intake (Boismare et al. 1984; Le Magnen et al. 1987b), it is not clear 
whether these effects are specific to the reinforcing properties of ethanol or reinforcement in general. In the present study, acamprosate eliminated the ethanol deprivation effect without affecting water responding. However, the "hedonic" value of receiving water in this concurrent choice procedure may not be equal to that of ethanol. In fact, all animals responded preferentially for ethanol compared to water. A more stringent test of the specificity of acamprosate would involve tests in which the alternative reinforcer is roughly equivalent to ethanol. Although this may be difficult to achieve on an absolute level, it is possible to equate operant responding for a saccharin solution with that observed for ethanol. This may be particularly relevant given that a type of deprivation effect is also observed with saccharin solution (Wayner et al. 1972), although the patten of responding is different than that observed in animals deprived of ethanol (Sinclair et al. 1973). Therefore, although it does appear that acamprosate affects ethanol intake, additional tests need to be conducted to examine the effects of acamprosate on other reinforcers.

The temporary increase in ethanol intake that characterizes the alcohol deprivation effect may be related to the "loss of control" associated with the human condition (Wolffgramm and Heyne 1995) and may represent a viable animal model for studying the phenomenon of "craving" (see Sinclair and Li 1989). Empirical studies indicate that craving is often positively correlated with actual drug use (Tiffany 1990; however, see Mello 1983), and it is a recognized component of the clinical phenomenon of drug abuse and dependence (APA 1994). However, it should be noted that Tiffany (1990) concluded that craving is not responsible for drug use and Ludwig and Wikler (1974) stated that "while the experience of craving provides an alcoholic with the necessary cognitive symbolism for goal-directed, appetitive behavior, there is no cogent reason (as with anger, hunger or sexual urge) why this subjective desire for alcohol should be directly acted upon or expressed in overt behavior, especially if there are competing drives or motivations." Therefore, craving may be viewed as a necessary but not sufficient condition for relapse or loss of control. Whereas craving for alcohol was not substantially changed by acamprosate in a study by Paille et al. (1995), the authors warn against the conclusion that acamprosate has no effect on craving because patients reporting the strongest craving at the start of treatment tended to relapse early and withdraw from the trial. This may have masked an effect of acamprosate on craving.

Acamprosate would appear to be relatively safe for human use (Litten et al., 1996). It has been shown to have very low abuse potential (Grant and Woolverton 1989) and does not substitute for ethanol (Spanagel et al. 1996c). Acamprosate has no antipunishment effects in an operant conflict test (Britton and Koob, unpub- lished results). In addition, there appear to be no withdrawal effects associated with the termination of acamprosate treatment, and it does not appear to exacerbate toxicities to alcohol (Le Magnen et al. 1987a). Another potential benefit of acamprosate is that it may have a positive effect on clinic attendance, which is important because the duration of compliance is considered to be of prognostic value (Paille et al. 1995). However, it is important to note that not all patients responded to acamprosate. For example, Lesch and Walter (1996) report that the effectiveness of acamprosate is related to the subtype of alcoholism. The present results suggest a similar hypothesis-that acamprosate may have differential effects on ethanol-related behaviors related to the history of ethanol experience (dependent versus nondependent) and/or preference for alcohol.

\section{ACKNOWLEDGMENTS}

This research was supported in part by the National Institute on Alcohol Abuse and Alcoholism Grants AA08459 and AA06420 (to GFK) and F32 AA05403 to CJH) and by Groupe LIPHA, Lyon, France. One author (GS) was supported by the National Institute on Alcohol Abuse and Alcoholism Training Grant AA07456 (to Floyd E. Bloom). Portions of these data were presented at the Research Society on Alcoholism Meetings, Washington D.C., June 1996. This is publication number 10413-NP from The Scripps Research Institute. The authors thank Maury Cole, Amanda Ormsby, Edward R. Curley, and Alexa Konstanturos for excellent technical assistance.

\section{REFERENCES}

American Psychiatric Association (1994): Diagnostic and Statistical Manual of Mental Disorders, 4th ed., rev. Washington DC, 1987

Barnes DM (1988): Breaking the cycle of addiction. Science 241:1029-1030

Berton F, Francesconi WG, Madamba SG, Zieglgänsberger $W$, Siggins GR (in press): Acamprosate enhances nmethyl-d-aspartate receptor-mediated neurotransmission but inhibits presynaptic $\mathrm{GABA}_{B}$ receptors in nucleus accumbens neurons. Alcohol Clin Exp Res

Boismare F, Daoust M, Moore N, Saligaut C, Lhuintre JP, Chretien P, Durlach J (1984): A homotaurine derivative reduces the voluntary intake of ethanol by rats: Are cerebral GABA receptors involved? Pharmacol Biochem Behav 21:787-789

Burish TG, Maisto SA, Cooper AM, Sobell MB (1981): Effects of voluntary short-term abstinence from alcohol on subsequent drinking patterns of college students. J Stud Alcohol 42:1013-1020

Chabenat C, Chretien P, Daoust M, Moore N, Andre D, Lhuintre JP, Saligaut C, Boucly P, Boismare F (1988): Physiochemical, pharmacological and pharmacokinetic study of a new GABAergic compound, calcium acetylhomotaurinate. Methods Find Exp Clin Pharmacol 10: 311-317 
Chick J (1995): Acamprosate as an aid in the treatment of alcoholism. Alcohol Alcohol 30:785-787

Daoust M, Legrand E, Gewiss M, Heidbreder C, DeWitte P, Tran G, Durbin P (1992): Acamprosate modulates synaptosomal GABA transmission in chronically alcoholised rats. Pharmacol Biochem Behav 41:669-674

Durbin P, Legrand E, Daoust M (1996): Characterization of a central acamprosate binding site in rats. Alcohol Clin Exp Res 20:7A

Grant KA, Woolverton WL (1989): Reinforcing and discriminative stimulus effects of $\mathrm{Ca}$-aceytl homotaurine in animals. Pharmacol Biochem Behav 32:607-611

Heyser CJ, Schulteis G, Koob GF (1997): Increased ethanol self-administration after a period of imposed ethanol deprivation in rats trained in a limited access paradigm. Alcohol Clin Exp Res 21:784-791

Hunt WA, Barnett LW, Branch LG (1971): Relapse rates in addiction programs. J Clin Psychol 27:455-456

Kirk RE (1982): Experimental Design: Procedures for the Behavioral Sciences, 2nd ed. Belmont, CA, Brooks/Cole

Kornet M, Goosen C, Van Ree JM (1990): The effect of interrupted alcohol supply on spontaneous alcohol consumption by rhesus monkeys. Alcohol Alcohol 25:407-412

Le Magnen J (1960): Etude de quelques facteurs associé à des modification de la consommation spontanée d'alcool éthylique par le rat. J Physiol (Paris) 52:873-884

Le Magnen J, Tran G, Durlach J (1987a): Lack of effects of CaAcetyl homotaurinate on chronic and acute toxicities of ethanol in rats. Alcohol 4:103-108

Le Magnen J, Tran G, Durlach J, Martin C (1987b): Dosedependent suppression of the high alcohol intake of chronically intoxicated rats by Ca-acetyl homotaurinate. Alcohol 4:97-102

Lesch OM, Walter H (1996): Subtypes of alcoholism and their role in therapy. Alcohol Alcohol 31:63-67

Lhuintre JP, Daoust M, Moore ND, Chretien P, Saligaut C, Tran G, Boismare F, Hillemand B (1985): Ability of Calcium bis-acetyl homotaurine, a GABA agonist, to prevent relapse in weaned alcoholics. Lancet 1:1014-1016

Lhuintre JP, Moore N, Tran G, Steru L, Langrenon S, Daoust $\mathrm{M}$, Parot Ph, Ladure, Ph, Libert C, Boismare F, Hillemand B (1990): Acamprosate appears to decrease alcohol intake in weaned alcoholics. Alcohol Alcohol 25: 613-622

Litten RZ, Allen J, Fertig J (1996): Pharmacotherapies for alcohol problems: A review of research with focus on developments since 1991. Alcohol Clin Exp Res 20:859876

Ludwig AM, Wikler A (1974): "Craving" and relapse to drink. Q J Stud Alcohol 35:108-130

Madamba SG, Schweitzer P, Zieglgänsberger W, Siggins GR (1996): Acamprosate (calcium acetylhomotaurinate) enhances the n-methyl-d-aspartate component of excitatory neurotransmission in rat hippocampal CA1 neurons in vitro. Alcohol Clin Exp Res 20:651-658

Marlatt GA, George WH (1984): Relapse prevention: Introduction and overview of the model. Br J Addict 79:261-273

Mello NK (1983): A behavioral analysis of the reinforcing properties of alcohol and other drugs in man. In Kissen
B, Begleiter H (eds), The Pathogenesis of Alcoholism. New York, Plenum Press, pp 133-198

Mendelson JH, Mello NK (1979): One unanswered question about alcoholism. Br J Addict Alcohol Other Drugs 74: 11-14

Naranjo CA, Sellers EM, Lawrin MO (1986): Modulation of ethanol intake by serotonin uptake inhibitors. J Clin Psychiatry 47:16-22

Naranjo CA, Sellers EM, Sullivan JT, Woodley DV, Kadlec K, Sykora K (1987): The serotonin uptake inibitor citalopram attenuates ethanol intake. Clin Pharmacol Ther 41: 266-274

Paille FM, Guelfi JD, Perkins AC, Royer RJ, Steru L, Parot P (1995): Double-blind randomized multicentre trial of acamprosate in maintaining abstinence from alcohol. Alcohol Alcohol 30:239-247

Rassnick S, D'Amico E, Riley E, Pulvirenti L, Zieglgänsberger W, Koob G (1992): GABA and nucleus accumbens glutamate neurotransmission modulate ethanol self-administration in rats. Ann NY Acad Sci 654:502-505

Samson HH (1986): Initiation of ethanol reinforcement using a sucrose-substitution procedure in food- and watersated rats. Alcohol Clin Exp Res 10:436-442

Sass H, Soyka M, Mann K, Zieglgänsberger W (1996): Relapse prevention by acamprosate. Arch Gen Psychiatry 53:673680

Schuckit MA (1996): Recent developments in the pharmacotherapy of alcohol dependence. J Consult Clin Psychol 64:669-676

Schulteis G, Hyytiä P, Heinrichs SC, Koob GF (1996): Effects of chronic ethanol exposure on oral self-administration of ethanol or saccharin by Wistar rats. Alcohol Clin Exp Res 20:164-171

Sinclair JD, Li T-K (1989): Long and short alcohol deprivation effects on AA and $\mathrm{P}$ alcohol-preferring rats. Alcohol 6:505-509

Sinclair JD, Senter RJ (1967): Increased preference for ethanol in rats following alcohol deprivation. Psychon Sci 8:11-12

Sinclair JD, Senter RJ (1968): Development of an alcohol-deprivation effect in rats. Q J Stud Alcohol 29:863-867

Sinclair JD, Walker S, Jordan W (1973): Alcohol intubation and its effect on voluntary consumption by rats. Q J Stud Alcohol 34:726-743

Spanagel R, Hölter SM, Allingham K, Landgraf R, Zieglgänsberger W (1996a): Acamprosate and alcohol. I. Effects on alcohol intake following alcohol deprivation in the rat. Eur J Pharamcol 305:39-44

Spanagel R, Putzke J, Stefferl A, Schöbitz B, Zieglgänsberger W (1996b): Acamprosate and alcohol. II. Effects on alcohol withdrawal in the rat. Eur J Pharmacol 305:45-50

Spanagel R, Zieglgänsberger W, Hundt W (1996c): Acamprosate and alcohol. III. Effects on alcohol discrimination in the rat. Eur J Pharamcol 305:51-56

Tiffany ST (1990): A cognitive model of drug urges and drug use behavior: Role of automatic and nonautomatic processes. Psychol Rev 97:147-168

Wayner MJ, Greenberg I, Tartaglione R, Nolley D, Fraley S, Cott A (1972): A new factor affecting the consumption of ethyl alcohol and other sapid fluids. Physiol Behav 8: 345-362 
Whitworth A, Fischer F, Lesch O, Nimmerrichter A, Oberbauer H, Platz T, Potgieter A, Walter H, Fleischhacker WW (1996): Comparison of acamprosate and placebo in long-term treatment of alcohol dependence. Lancet 347: 1438-1442

Wolffgramm J, Heyne A (1995): From controlled drug intake to loss of control: The irreversible development of drug addiction in the rat. Behav Brain Res 70:77-94
Yates WR, Reed DA, Booth BM, Masterson BJ, Brown K (1994): Prognostic validity of short-term abstinence in alcoholism. Alcohol Clin Exp Res 18:280-283

Zeise ML, Kasparov S, Capogna M, Zieglgänsberger W (1993): Acamprosate (calciumacetylhomotaurinate) decreases postsynaptic potentials in the rat neocortex: Possible involvement of excitatory amino acid receptors. Eur J Pharmacol 231:47-52 